OPEN ACCESS

Edited by:

Chaozong Liu,

University College London,

United Kingdom

Reviewed by:

Carlos Roberto Grandini,

São Paulo State University, Brazil

Lai-Chang Zhang,

Edith Cowan University, Australia

*Correspondence:

Stéphanie Delannoy stephanie.delannoy@ chimieparistech.psl.eu

Specialty section:

This article was submitted to Biomaterials,

a section of the journa

Frontiers in Materials

Received: 27 November 2020 Accepted: 23 February 2021

Published: 16 March 2021

Citation:

Delannoy S, Baïz S, Laheurte P,

Jordan L and Prima F (2021)

Elastically Graded Titanium Alloy

Produced by Mechanical Surface

Deformation. Front. Mater. 8:634236.

doi: 10.3389/fmats.2021.634236

\section{Elastically Graded Titanium Alloy Produced by Mechanical Surface Deformation}

\author{
Stéphanie Delannoy ${ }^{1,2 *}$, Sarah Baïz ${ }^{3}$, Pascal Laheurte $^{4}$, Laurence Jordan ${ }^{1,5,6}$ and \\ Frédéric Prima ${ }^{1}$
}

${ }^{1}$ PSL Research University, Chimie ParisTech-CNRS, Institut de Recherche de Chimie Paris UMR CNRS 8247, Paris, France, ${ }^{2}$ Biotech Dental, Salon-de-Provence, France, ${ }^{3}$ Laboratoire Procédés et Ingénierie en Mécanique et Matériaux, PIMM, ENSAM, UMR 8006, CNRS, CNAM, Paris, France, ${ }^{4}$ Laboratoire d'Etude des Microstructures et de Mécanique des Matériaux, LEM3 UMR CNRS 7239, Université de Lorraine, Metz, France, ${ }^{5}$ Dental Faculty, Université de Paris, Paris, France, ${ }^{6}$ Hospital Rothschild, AP-HP, Paris, France

The objective of this study was to develop a thermo-mechanical strategy to create a radial elasticity gradient in a $\beta$ metastable Ti-Nb-Zr alloy, and to characterize it in terms of microstructural and mechanical properties. A first investigation was conducted on thin samples of Ti-20Nb-6Zr (at.\%) submitted to various thermo-mechanical treatments. Microstructure-properties relationships and elastic variability of this alloy were determined performing uniaxial tensile tests, X-ray diffraction and scanning and transmission electron microscopies. Based on these preliminary results, mechanical deformation was identified as a potential way to lower the elastic modulus of the alloy. In order to create elastically graded pieces, shot-peening was therefore carried out on thicker samples to engender surface deformation. In this second part of the work, local mechanical properties were evaluated by instrumented micro-indentation. Experimental observations demonstrated that shot-peening enabled to locally induce martensitic transformation on surface, and a decrease in indentation elastic modulus from 85 to 65 GPa over $400 \mu \mathrm{m}$ was highlighted. Surface deformation proved to be an efficient way of creating an elasticity gradient in $\beta$ metastable titanium alloys. This combination of material and process could be suitable to produce dental implants with mechanically enhanced biocompatibility.

Keywords: titanium alloys, elasticity gradient, elastic modulus, surface deformation, instrumented indentation, stress-induced martensite

\section{INTRODUCTION}

In the field of implanted medical devices, the notion of biocompatibility has evolved steadily over time and is no longer only synonymous with bio-inertness. Nowadays, an active biocompatibility is being sought, giving a greater focus on the integration of biomaterials and the responses of the human body (Williams, 1987, 2003; Doherty et al., 1992). In the case of dental implants, this means to promote bone remodeling in order to achieve good osseointegration. Aside from biological and chemical considerations, mechanical aspects are therefore equally critical to the development of highly performant biomaterials. Indeed, the bone remodeling is physiologically driven by mechanical stimuli and under- or overloading of bone tissue could engender resorption or necrosis issues (Rieger et al., 2011; Laheurte et al., 2014). The difficulty relies on the fact that the use of dental implants can affect this bone density regulation in various ways. First, the absence 
of periodontal ligament no longer allows to provide a damping effect, which can create load peaks in the surrounding bone (Kitamura et al., 2004; Mariani et al., 2008; Consolaro et al., 2010). And several studies have shown that the elastic mismatch observed at the bone/implant interface could give rise to stress shielding and poor stress distribution around the device (Kroger et al., 1998; Niinomi and Nakai, 2011). As a matter of fact, although lower than those of previously used 316L steel or CoCr-Mo alloys, Young's moduli of current standard biomedical titanium alloys (CP Ti or TA6V) still remain about 5-10 times higher than the one of bone (Geetha et al., 2009). This calls for further efforts to minimize this modulus gap.

In recent years, various research works have been carried out to reduce the originally quite high elastic modulus of titanium alloys, classically around $100 \mathrm{GPa}$ for conventional $\alpha$ or $\alpha+\beta$ alloys (Kuroda et al., 1998; Geetha et al., 2009; Zhang and Chen, 2019). One of the most advanced track concerns the development of new low-modulus compositions, mainly belonging to $\beta$-type alloys, which started in the 90's and enabled to reach moduli down to about $60 \mathrm{GPa}$ (Zheng et al., 2012; Shi et al., 2013; Laheurte et al., 2014; Piotrowski et al., 2014; Brizuela et al., 2019). It should be noted, however, that these alloys generally exhibit a limited mechanical strength. Alongside this research of adapted formulations and thermo-mechanical treatments, the creation of porous structures (Li et al., 2014; Liu et al., 2015; Wally et al., 2015; Okulov et al., 2017) or the use of lowmodulus coatings (Koshy and Philip, 2015) have also proven to be effective in lowering the stiffness of investigated materials. Nevertheless, these methods, based on complex processes which can be difficult to control, have often led to a deterioration of other properties, including drops in mechanical resistance (Yue et al., 1984; Bandyopadhyay et al., 2010; Oldani and Dominguez, 2012) or additional weaknesses related to the multi-material interfaces (Mimura et al., 2004; Oshida et al., 2010; Xue et al., 2020). To face these issues, and since iso-elasticity is essentially required at the bone/implant interface, structures displaying gradients in porosity or in chemical compositions were also studied. Once again, even after having overcome the obstacle of producing such complex structures, a compromise between promoting bone remodeling and maintaining a sufficient level of mechanical resistance was difficult to achieve (Lin et al., 2010; Mehrali et al., 2013).

The original concept developed in this work tries to exploit the advantages of some of the previously mentioned research axes, based on the diversity offered by titanium alloys. Indeed, in addition to intrinsic reasons, related to their chemical composition, some titanium alloys can present changes in modulus due to specific elastic behaviors linked to martensitic transformations. The innovative idea investigated here, which has recently been patented (Prima and Nowak, 2012), consists in using the elastic variability displayed by this kind of alloys and creating an elastic gradient resulting from a microstructural gradient, thus preserving a monolithic material with a homogeneous chemical composition. The elastic softening should be localized on surface, to enhance the load transfer to the bone, and the initial stiffer microstructure should be kept in the core material to ensure the stability and durability of the medical implanted device. In order to induce only a superficial transformation, shot-peening has emerged as a suitable option. This technical process is commonly used to superficially treat medical implants and, as well as creating a rough surface with beneficial effect on bone growth, the resulting residual stress layer seems to enhance fatigue performance of the materials (Javier Gil et al., 2007).

Therefore the aim of this study is to assess the feasibility of creating an elasticity gradient through this strategy of surface deformation by shot-peening on a $\beta$-metastable titanium alloy, and thus consider this approach for the production of dental implants.

\section{MATERIALS AND METHODS}

\section{Material Selection}

Among titanium alloys, Ti-20Nb-6Zr (at.\%), also referred as TNZ, was selected as a candidate for this project for several motives. Already studied for its superelastic behavior (Sun et al., 2010, 2011; Zhang et al., 2013), this alloy only contains biocompatible chemical elements and avoids, in particular, species such as aluminum or vanadium, considered likely to contribute to cytotoxicity or neurodegenerative troubles, thus compromising the extensive use of TA6V (Laing et al., 1967; Steinemann, 1980; Walker et al., 1989; Rao et al., 1996; Riley et al., 2003; Gomes et al., 2011; US Food and Drug Administration, 2019). This material also displays interesting mechanical properties, namely strength-elongation combination comparable to the one of grade $4 \mathrm{CP} \mathrm{Ti}$ in a quenched state (full $\beta$ phase). Moreover, its martensitic start temperature is situated just below room temperature, which provides the alloy the possibility to easily undergo stress-induced martensitic (SIM) transformation at room temperature. As previously said, this enables to further reduce its originally already low intrinsic modulus.

\section{Elaboration and Thermo-Mechanical Processing Route}

A Ti-20Nb-6Zr (at.\%) ingot was prepared by vacuum arc melting and hot forged down to a 50-mm-diameter billet. Plate-shaped parts, cut from this billet, were solution treated under air at $1,173 \mathrm{~K}$ for 900 s, water quenched and mechanically polished to remove the outer oxidized part. From this step, cold-rolled state with controlled thickness reduction was obtained differently, depending on the part of the considered work, as follows: for the preliminary work, performed on thin samples, polished pieces were cold-rolled (CR) at room temperature down to about $0.5 \mathrm{~mm}$ of thickness (reduction ratio $\approx 90 \%$ ), whereas for the work on thicker samples, cold-rolling was stopped at about $5 \mathrm{~mm}$ of thickness (reduction ratio $\approx 70 \%$ ). To produce quenched state, both thin and thick samples were then thermally treated at $1,173 \mathrm{~K}$ during 1,800 s under controlled atmosphere and finally water quenched.

Additional surface mechanical treatment was applied on some of the $5 \mathrm{~mm}$-thick samples by shot-peening. This was done on a Wheelabrator industrial prototype (IRT-M2P, Metz), using s130 steel balls at an intensity of $32 \mathrm{~A}$ on Almen scale, which 
represents severe conditions. Both static and dynamic tests were performed. Static experiments were defined by the exposure time to shot-peening during which the nozzle was kept in front of the treated area, whereas dynamic experiments used the coverage percentage of the surface. In that later case, for which the shotpeening nozzle moved parallel to the surface, a number of passes necessary to cover $100 \%$ of the surface was determined and, as an example, a coverage of $300 \%$ was done reproducing three times this number of passes.

\section{Microstructural Characterization}

Phase constitution was analyzed by X-ray diffraction (XRD) using a copper anticathode (Panalytical X'Pert PRO, $45 \mathrm{kV}$, $40 \mathrm{~mA}$ ). All the samples were mechanically polished prior to XRD analyses except shot-peened samples, which were kept without any further surface alteration. Microstructural observations were done on an EBSD-equipped scanning electron microscope (SEM-Zeiss LEO-1530). For that purpose, thick samples were cut in half to reveal the cross-section of the shot-peened surfacefor concerned sample-, mounted in conductive resin (Struers Polyfast) and mechanically polished on $800,1,200,2,500$, and 4,000 silicon carbide abrasive papers. Further polishing was done using a mixture of colloidal silica suspension (Struers OPS) and hydrogen peroxide until mirror-like finish, and a final step was performed on a vibratory polisher (Buehler VibroMet) for $12 \mathrm{~h}$ with silica suspension (Struers OP-S) to remove slight deformations and damages remaining from mechanical polishing. Observations were also done using a transmission electron microscope (TEM-JEOL 2000FX). Sections of thin samples were cut, mechanically rounded and polished on silicon carbide abrasive papers to get pre-thinned 3-mmdiameter disks, typically between 100 and $200 \mu \mathrm{m}$ thick. They were then prepared using twin-jet electrochemical polishing (Struers TenuPol with a solution of methanol, 2-butoxyethanol, perchloric and hydrochloric acids at around $263 \mathrm{~K}$ ).

\section{Mechanical Properties}

Uniaxial tensile tests were conducted to measure the mechanical properties of flat samples. Dogbone tensile specimens were taken along the rolling direction and tested at a strain rate of $10^{-3} \mathrm{~s}^{-1}$ on a MTS Criterion (Model 43) machine equipped with a $25 \mathrm{~mm}$ gauge length extensometer. Regarding thicker samples, local properties were estimated by carrying out indentation profiles on mirror-polished samples prepared as previously mentioned for SEM observations. Micro-hardness values and elasticity moduli were extracted from instrumented indentation experiments performed on an Anton Paar Micro Hardness Tester (ENSAM, Paris) using Vickers indent and $500 \mathrm{mN}$ load with $5 \mathrm{~s}$ holding. Experimental parameters were determined on the basis of a previous design of experiments, done on pure titanium, in order to maximize the measurement accuracy. Oliver-Pharr method was used and indentation moduli $E_{\mathrm{IT}}$ were calculated from the unloading curves through the following relation:

$$
E_{I T}=\frac{1-\left(v_{S}\right)^{2}}{\frac{1}{E_{r}}-\frac{1-\left(v_{i}\right)^{2}}{E_{i}}}
$$

where $E_{\mathrm{r}}$ is the reduced elastic modulus, $E_{\mathrm{i}}$ is the indenter modulus, and $\nu_{\mathrm{s}}$ and $\nu_{\mathrm{i}}$ represent, respectively the specimen and the indenter Poisson coefficients (Oliver and Pharr, 1992, 2004).

\section{RESULTS AND DISCUSSION}

\section{Assessment of Elastic Variability on Thermo-Mechanically Treated TNZ Samples}

The first part of the work aimed at studying the behavior of the TNZ alloy and assessing the potential variability of its microstructure and properties, and particularly its elastic modulus, after various thermo-mechanical treatments. For this purpose, thin samples $(0.5 \mathrm{~mm})$ were prepared as mentioned in the previous section. Mechanical tests and observations were performed in the as-obtained cold-rolled state, referred as CR, and after an additional solution treatment in the $\beta$ phase field followed by water quenching, referred as ST or quenched state. This rapid cooling was done to avoid the precipitation of alpha or isothermal omega phases, which would cause a chemical partition of $\beta$-stabilizing elements in the matrix and therefore the inhibition of subsequently desired stress-induced martensitic transformation.

XRD profiles of deformed and quenched states are presented in Figure 1. ST state is mainly constituted of $\beta$ phase, and its lattice parameter is estimated based on experimentally observed peak positions as follows: $a_{\beta}=3.299 \AA$ for this bcc structure belonging to $\operatorname{Im} \overline{3} m$ space group. No $\alpha$ phase is detected, thus assessing the efficiency of rapid quenching. Regarding the CR state, formation of a large amount of $\alpha^{\prime \prime}$ martensite during cold-rolling process can be clearly evidenced by the appearance of several additional peaks on the corresponding diffractogram. Compared to quenched state, a broadening of the XRD peaks can be noticed. This accounts for the important grain refinement-decrease of the coherent domain sizes-and high level of distortion generated by the deformation process, as well as the near-continuous diffraction rings obtained for this microstructure and visible on the SAED pattern in Figure 2. In addition, in the bright-field image, dark areas linked to dislocation tangles are also indicators of the severity of the cold-rolling deformation.

Tensile stress-strain curves of ST and CR specimens are presented in Figure 3. The quenched specimen exhibits large ductility $(>40 \%)$ and moderate strength $(\mathrm{Rm}=530 \mathrm{MPa})$. A double-yielding phenomenon can be seen at the beginning of the ST curve. The first yielding, located in the elastic part ("plateau" at about $250 \mathrm{MPa}$ ), is the signature of the stressinduced martensitic transformation, whereas the second yielding (around $375 \mathrm{MPa}$ ) can be attributed to the transition to the plastic range.

Tensile curve of deformed state shows that severe cold-rolling up to $90 \%$ reduction ratio enabled to drastically increase the mechanical resistance of the alloy up to $1,050 \mathrm{MPa}$, but at the expense of the ductility which drops to only a few percent. The presence, at the initial stage of the tensile test, of a fine martensitic microstructure and a high dislocation density can be responsible 
for this impressive strengthening. In addition, a classical linear elastic behavior can be noticed here, suggesting that any further martensitic transformation or martensite variants reorientation takes place in the material and a saturation state has been reached (Schneider et al., 2005).

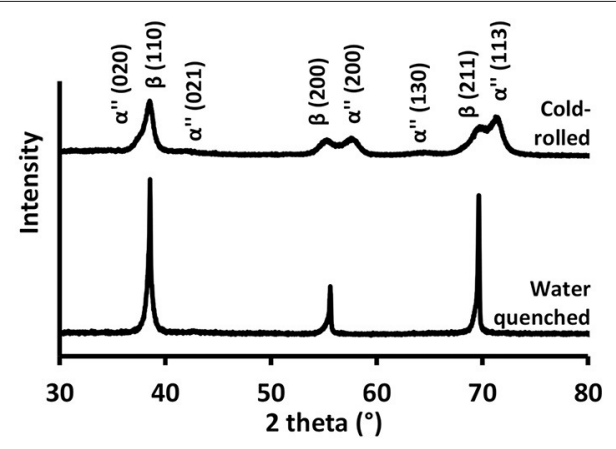

FIGURE 1 | XRD profiles of cold-rolled (CR- 90\% thickness reduction) and water quenched (ST) TNZ specimens.

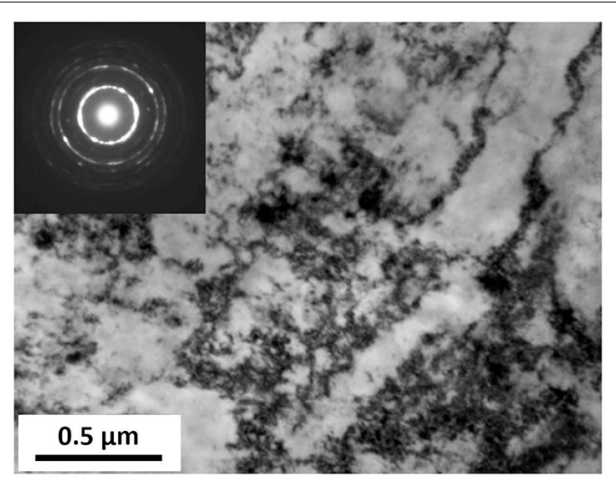

FIGURE 2 | Bright-field micrograph and corresponding selected area electron diffraction (SAED) pattern of cold-rolled TNZ sample (CR state).
Incipient Young's moduli were extracted from the early stage of the curves for both microstructural states, 66 and $55 \mathrm{GPa}$ were obtained for ST and CR specimens, respectively. Bearing in mind that cold-rolling was performed on a solution-treated state, these results indicate that stress-induced martensitic transformation and variants rearrangement that occur when deforming single phase $\beta$ TNZ alloy can lead to an elastic softening exceeding $15 \%$. This result is consistent with the gradual lowering of elastic modulus which was already observed in previous works during incremental loading-unloading tensile tests performed on this alloy (Sun et al., 2010; Zhang et al., 2013). This information is of great relevance since it enables to develop a practical strategy to create an elasticity gradient in TNZ, by applying a local deformation on surface of thicker samples in $\beta$ phase.

\section{Creation of Elasticity Gradient}

As the creation of a gradient was now being sought, thin samples could no longer be used from a practical point of view. To put into action the strategy described just above, thicker waterquenched TNZ samples were produced. The thickness of $5 \mathrm{~mm}$ was chosen in order to be close to the diameter of current commercial dental implants. Shot-peening mechanical treatment was then applied on one side of the pieces. Various experimental conditions were used: $100 \%, 300 \%$ and 1 s as defined in section Elaboration and Thermo-Mechanical Processing Route.

XRD analyses were performed on samples before and after shot-peening as illustrated by Figure 4. For the initial ST state, only surface XRD profile is displayed but mid-thickness was also analyzed to ensure that the whole sample was in single $\beta$ phase. After shot-peening, additional peaks ascribed to $\alpha^{\prime \prime}$ martensite were detected for all treated samples. (020) (021), and (130) peaks were the easier to identify although they are quite small. This low intensity may reflect that only a moderate quantity of martensite is actually trapped after this mechanical process, compared to previous heavy cold-rolling. The fact that no other potential peaks associated with martensite were revealed can be attributed to the broadening of $\beta$ peaks, due to residual stress in the material after the mechanical treatment, or is simply linked to the strong

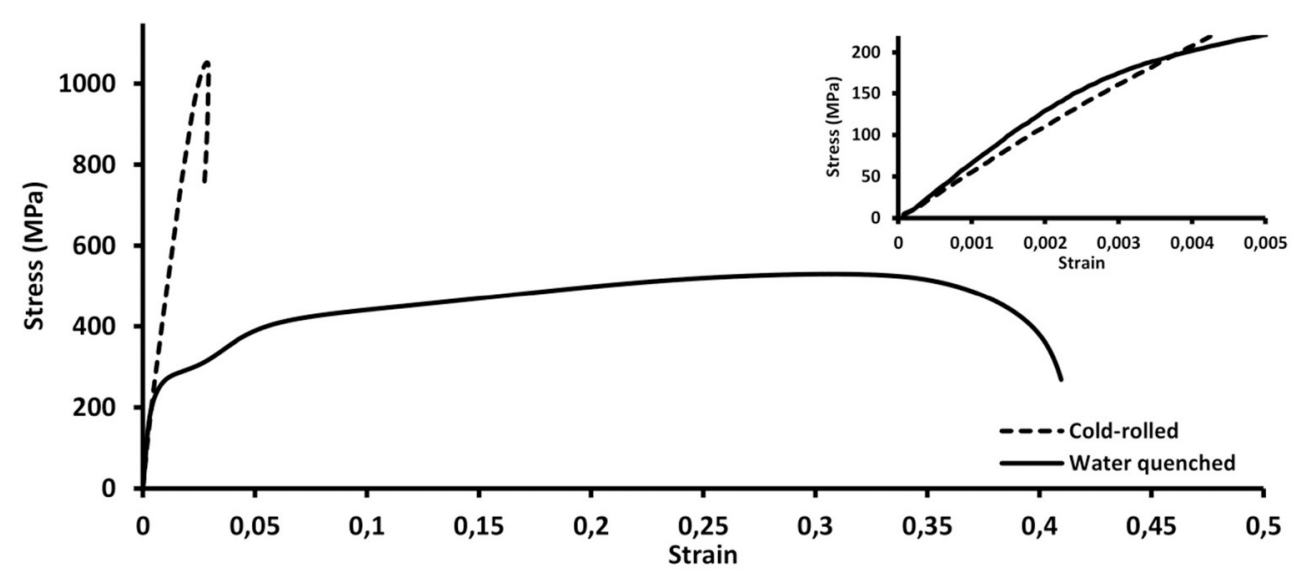

FIGURE 3 | Engineering stress-strain tensile curves of cold-rolled (CR) and water quenched (ST) TNZ specimens (insert: magnified view of the initial part of the curves). 


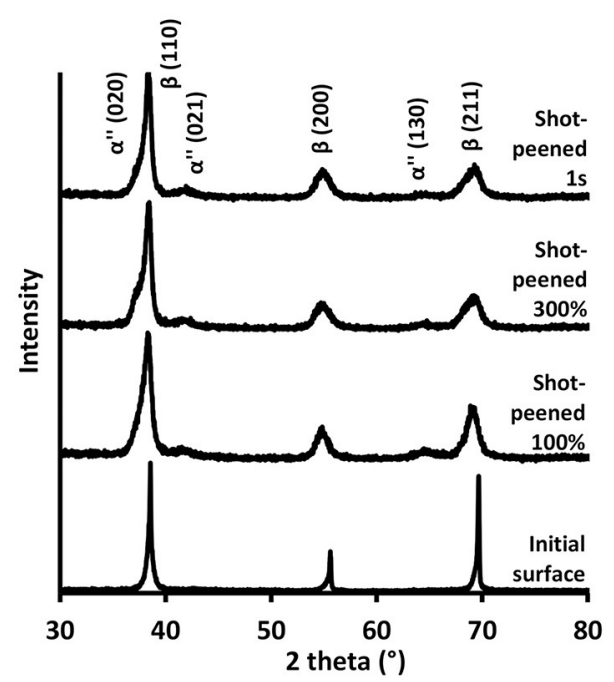

FIGURE 4 | XRD profiles obtained on surface of TNZ samples before (initial surface-ST state) and after shot-peening (at various coverage percentages). crystallographic variant selection which operates during stressinduced martensitic transformation. Nevertheless, based on the observation of $(020)_{\alpha^{\prime \prime}}$ peak, which is more pronounced for samples shot-peened at $300 \%$ or during 1 s, it can be suggested that these tougher conditions led to the creation of a higher amount of martensite, compared to shot-peening at $100 \%$.

Cross-sectional observations carried out before and after mechanical surface treatment are gathered in Figure 5. EBSD analysis revealed equiaxed $\beta$ grains in the initial ST state and additional bands were found for all the samples which were submitted to shot-peening. The density of these bands is very high on extreme surface and is decreasing gradually toward the depth. Furthermore, it may be noted that the size of the affected area seems to correlate with the severity of the shot-peening. Indeed, as can be seen from the bottom part of Figure 5, a larger dark saturated zone is observable for the sample submitted to the 1s treatment, which can be regarded as the tougher mechanical process, compared to 300 and 100\% coverages. Due to important residual stresses and the fine scale of these new microstructural features, and despite the use of a small step size of $0.2 \mu \mathrm{m}$, EBSD indexation of the bands was difficult to achieve

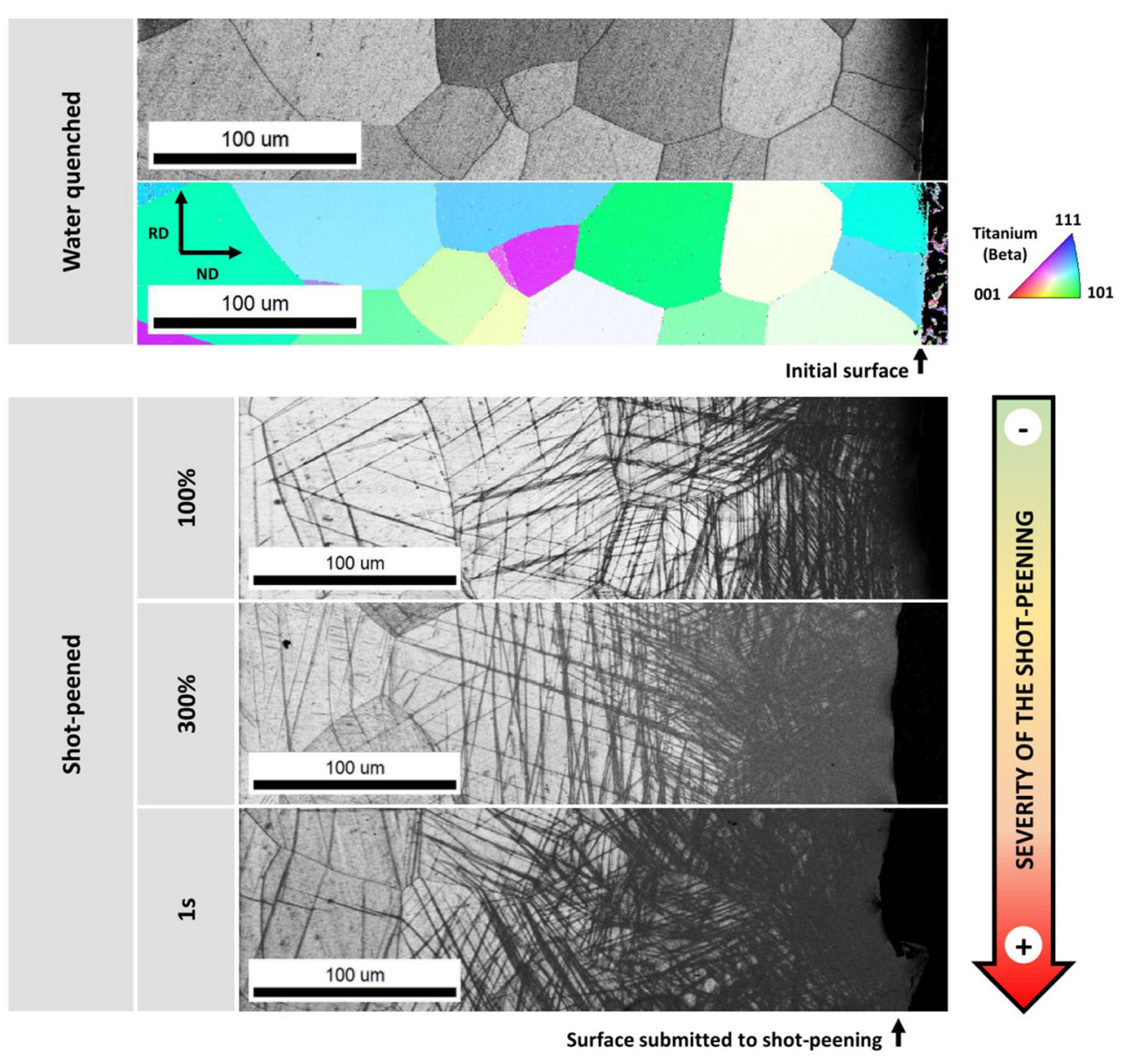

FIGURE 5 | Cross-sectional microstructural observations by scanning electron microscopy of TNZ samples before (top) and after various shot-peening conditions (bottom). Gray scale images correspond to EBSD IQ (Image Quality) maps and the colored one is a crystallographic orientation cartography of the $\beta$ phase, color coding is given by the standard triangle on the right. 
for shot-peened samples. However, based on the shape of these bands, their size, and information from previous XRD analyses, it seems quite obvious to associate them with the presence of $\alpha^{\prime \prime}$ martensite. In addition, some features appeared as potential $\beta$ twins. As a matter of fact, and as illustrated by Figure 6, misorientation profiles made across the $\beta$ matrix and some of the bands revealed misorientation angles of about $50.5^{\circ}$ which are typical of $\{332\}<113>_{\beta}$ twins. The origin of these twins is not yet clear and investigations did not allow us to determine whether they have been induced during the shot-peening process or whether they have resulted from the reversion of $\alpha^{\prime \prime}$ phase, itself created during the deformation process. This second assumption is based on the fact that the reversion of parent $\{130\}<310>_{\alpha^{\prime \prime}}$ twins to $\{332\}<113>_{\beta}$ twins has already been reported in the literature during unloading of a $\alpha$ " martensitic titanium alloy (Bertrand et al., 2016; Castany et al., 2016).

Previous elements are all indicators showing that shotpeening was efficient to trigger martensitic transformation in surface of TNZ samples. To evaluate the associated local changes in terms of mechanical properties and highlight the desired elasticity gradient, instrumented micro-indentation tests were conducted. Hardness and modulus profiles obtained from the surface toward the depth of samples shot-peened at a coverage percentage of $300 \%$ are given in Figure 7 . Whereas the mechanical treatment increased the surface hardness, as expected from the literature (Schulze, 2006), mainly because of the residual stresses and the introduction of numerous dislocations into the material, a decrease in indentation modulus $\left(\mathrm{E}_{\mathrm{IT}}\right)$ was also evidenced. Its value falls from about $87 \mathrm{GPa}$ at mid-thickness to $67 \mathrm{GPa}$ on the shot-peened surface of the piece.

It is important to point out that indentation modulus values, computed from indentation experiments using Oliver-Pharr method, are higher than Young's modulus values extracted from tensile curves. This overestimation at nano- or micro-scale compared to macro-scale has already been reported in previous works (Fizanne-Michel et al., 2014). Nonetheless, despite the shift that might exist, the two moduli remain comparable as they follow the same evolution, making it possible to bring to light the presence of an elasticity gradient. It can be observed that data points are slightly scattered. In addition to experimental uncertainty, which was estimated to be around $\pm 2 \mathrm{GPa}$ in a preliminary work, this dispersion could be attributed to the large grain size of our material (up to about $100 \mu \mathrm{m}$ ). As a matter of fact, recent study showed a significant influence of crystal orientation on indentation modulus in a superelastic titanium alloy, highlighting the strong elastic anisotropy of the $\beta$ phase (Jabir et al., 2019). Yet, in our tested range, diagonals of the indentation prints are only about $20 \mu \mathrm{m}$ long and reflect, therefore, the contribution of only one single grain in most cases.

As can be seen from the bottom part of Figure 7, the evolution of the mechanical properties is well correlated with the evolution of the microstructure. From the depth to the surface, a clear relationship can be established between the decrease in the elastic modulus and the increase in the band density, both related to a higher amount of martensite near the surface. Concerning the depth affected by the mechanical treatment, it is worth noting that changes in properties extend over $\sim 400 \mu \mathrm{m}$ for these shotpeening conditions. This gradient depth would be particularly appropriate to the current common size of dental implants (diameter from 3 to $5 \mathrm{~mm}$ ).

These results validate the strategy we developed and establish a proof of concept that mechanical surface treatment of a biocompatible $\beta$-metastable titanium alloy can induce martensitic transformation on surface, and that this microstructural gradient can lead to an elasticity gradient. This turns out to be promising for dental implantology, as the resulting decrease in modulus obtained in surface should help avoid stress-shielding issues and thus promote osseointegration of the implant. In other words, it should mechanically improve the biocompatibility of implanted devices.

Furthermore, the method that was chosen in our study, namely shot-peening, is particularly relevant because it creates a rough surface which could certainly enhance not only bone remodeling but also fatigue performance of the implant. Further
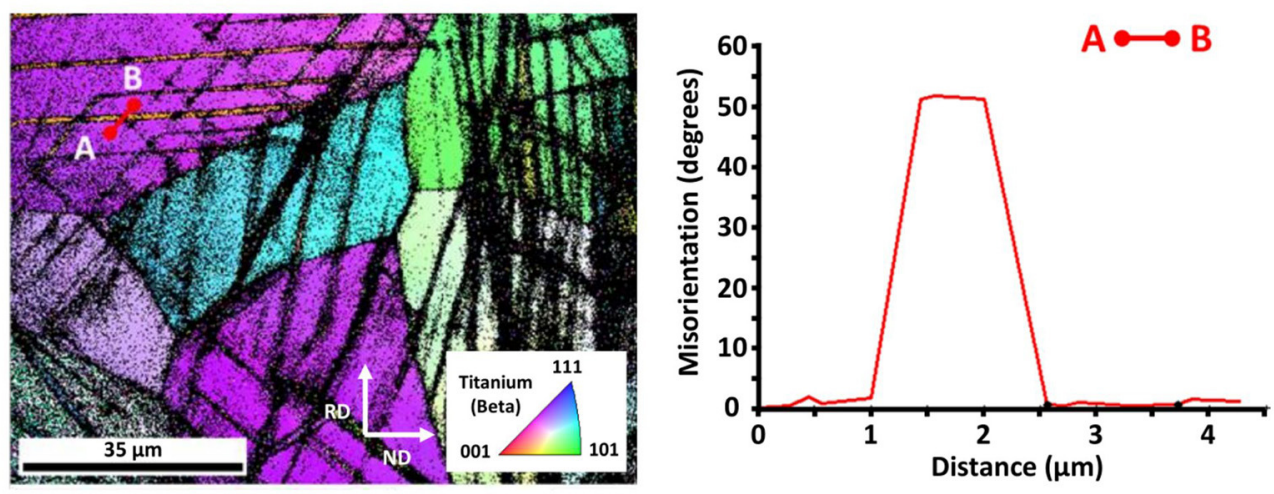

FIGURE 6 | EBSD crystallographic orientation cartography of $\beta$ phase obtained on a TNZ sample submitted to shot-peening at a coverage percentage of $100 \%$ (left). Acquisition was made about $150 \mu \mathrm{m}$ away from the surface to get better confidence index. Misorientation profile between $\mathrm{A}$ and $\mathrm{B}$ points indicated on the orientation map (right). 

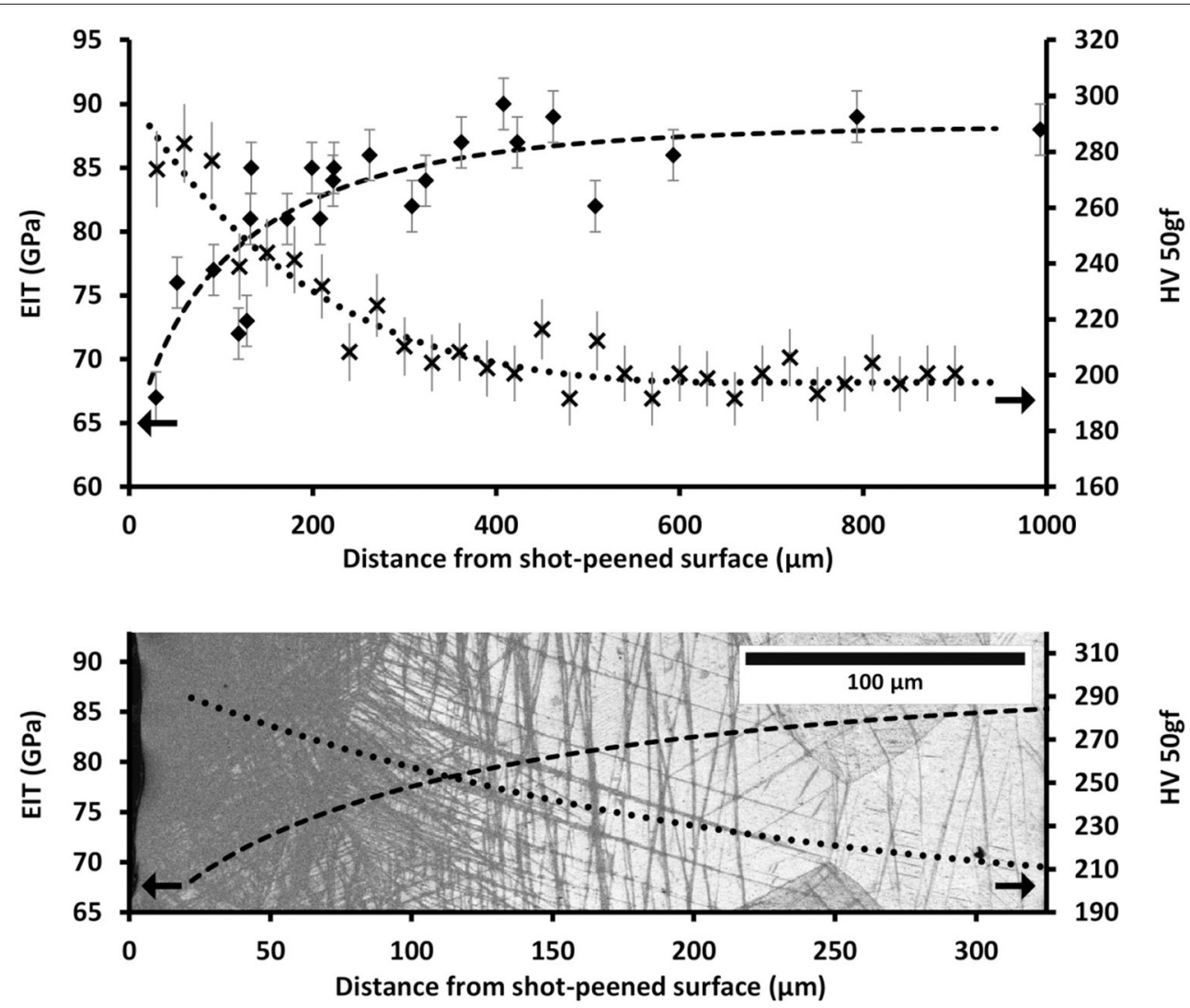

FIGURE 7 | Hardness and modulus profiles obtained from instrumented micro-indentation measurements conducted on a TNZ sample submitted to shot-peening at a coverage percentage of $300 \%$ (top). First part of the curves (surface) superimposed on the EBSD Image Quality map corresponding to this sample (bottom).

specific mechanical and biological tests should be conducted to check these properties. The impact of the shot-peening process on a threading should also be assessed to ensure it does not damage this important part of the device. In case of deterioration, thread-rolling could be considered as an attractive alternative in the production of dental implants, since it could be a suitable process to create the threaded part and induce the desired surface deformation at the same time (Domblesky and Feng, 2002).

Although the depth of created gradient, of about $400 \mu \mathrm{m}$, seems convenient for the intended application, the mechanical strength of the core material or the amplitude of modulus change could be optimized. Regarding TNZ alloy, future work could concern the modification of the solution treatment parameters in order to reduce the grain size. This would strengthen the material due to Hall-Petch effect and would also be more desirable for indentation measurements. In addition, it may be relevant to try applying the strategy we built to other $\beta$-metastable alloys or, even, to develop new strategies suitable for other types of titanium alloys. This could be done by investigating other microstructural states and identifying those which can also cause changes in the elastic modulus.

\section{CONCLUSION}

According to the results presented in this study, the following conclusions can be drawn:

(1) Stress-induced martensitic transformation in a $\beta$ metastable biocompatible Ti-20Nb-6Zr (at.\%) alloy led to a decrease in elastic modulus. This has given rise to a novel strategy consisting in applying a surface mechanical treatment on a $\beta$ phase titanium alloy in order to create an elasticity gradient.

(2) Shot-peening turned out to be efficient to induce local deformation, microstructural gradient based on martensitic transformation, and thus to create an elasticity gradient.

(3) Local evolution of elastic modulus was measured by instrumented micro-indentation and a gradient in indentation modulus from $87 \mathrm{GPa}$ in the core material to $67 \mathrm{GPa}$ on surface, over $400 \mu \mathrm{m}$, was revealed after shot-peening at a coverage percentage of $300 \%$.

(4) Creation of elasticity gradient is a promising way to avoid stress-shielding issues, promote osseointegration and produce implanted devices with mechanically enhanced biocompatibility. 


\section{DATA AVAILABILITY STATEMENT}

The raw data supporting the conclusions of this article will be made available by the authors, without undue reservation.

\section{AUTHOR CONTRIBUTIONS}

SD collected the experimental data, performed the data analysis, produced the figures, and wrote the manuscript. SB and PL were involved in planning and supervising, respectively, instrumented indentation measurements, and shot-peening experiments. FP conceived the original idea, directed this research project and contributed to the interpretation of the results. LJ helped

\section{REFERENCES}

Bandyopadhyay, A., Espana, F., Balla, V. K., Bose, S., and Davies, N. M. (2010). Influence of porosity on mechanical properties and in vivo response of Ti-6Al$4 \mathrm{~V}$ implants. Acta Biomater. 6, 1640-1648. doi: 10.1016/j.actbio.2009.11.011

Bertrand, E., Castany, P., Yang, Y., Menou, E., and Gloriant, T. (2016). Deformation twinning in the full- $\alpha^{\prime \prime}$ martensitic Ti-25Ta-20Nb shape memory alloy. Acta Mater. 105, 94-103. doi: 10.1016/j.actamat.2015.12.001

Brizuela, A., Herrero-Climent, M., Rios-Carrasco, E., Rios-Santos, J. V., Pérez, R. A., Manero, J. M., et al. (2019). Influence of the elastic modulus on the osseointegration of dental implants. Materials (Basel). 12, 1-7. doi: 10.3390/ma12060980

Castany, P., Yang, Y., Bertrand, E., and Gloriant, T. (2016). Reversion of a parent $\{130\}<310>\alpha^{\prime \prime}$ martensitic twinning system at the origin of $\{332\}<113>\beta$ twins observed in metastable $\beta$ titanium alloys. Phys. Rev. Lett. 117:245501. doi: 10.1103/PhysRevLett.117.245501

Consolaro, A., Carvalho, R. S., de Francischone, C. E. J., Consolaro, M. F. M. O., and Francischone, C. E. (2010). Saucerization of osseointegrated implants and planning of simultaneous orthodontic clinical cases. Dental. Press J. Orthod. 15, 19-30. doi: 10.1590/S2176-94512010000300003

Doherty, P. J., Williams, R. L., Williams, D. F., and Lee, A. J. C. (1992). BiomaterialTissue Interfaces: Proceedings of the Ninth European Conference on Biomaterials, Chester, U.K., September 9-11, 1991. Amsterdam: Elsevier.

Domblesky, J. P., and Feng, F. (2002). Two-dimensional and three-dimensional finite element models of external thread rolling. Proc. Inst. Mech. Eng. Part B J. Eng. Manuf. 216, 507-517. doi: 10.1243/0954405021520201

Fizanne-Michel, C., Cornen, M., Castany, P., Péron, I., and Gloriant, T. (2014). Determination of hardness and elastic modulus inverse pole figures of a polycrystalline commercially pure titanium by coupling nanoindentation and EBSD techniques. Mater. Sci. Eng. A 613, 159-162. doi: 10.1016/j.msea.2014.06.098

Geetha, M., Singh, A. K., Asokamani, R., and Gogia, A. K. (2009). Ti based biomaterials, the ultimate choice for orthopaedic implants-a review. Prog. Mater. Sci. 54, 397-425. doi: 10.1016/j.pmatsci.2008.06.004

Gomes, C. C., Moreira, L. M., Santos, V. J. S. V., Ramos, A. S., Lyon, J. P., Soares, C. P., et al. (2011). Assessment of the genetic risks of a metallic alloy used in medical implants. Genet. Mol. Biol. 34, 116-121. doi: 10.1590/S1415-47572010005000118

Jabir, H., Fillon, A., Castany, P., and Gloriant, T. (2019). Crystallographic orientation dependence of mechanical properties in the superelastic Ti-24Nb-4Zr-8Sn alloy. Phys. Rev. Mater. 3, 1-11. doi: 10.1103/PhysRevMaterials.3.063608

Javier Gil, F., Planell, J. A., Padrós, A., and Aparicio, C. (2007). The effect of shot blasting and heat treatment on the fatigue behavior of titanium for dental implant applications. Dent. Mater. 23, 486-491. doi: 10.1016/j.dental.2006.03.003

Kitamura, E., Stegaroiu, R., Nomura, S., and Miyakawa, O. (2004). Biomechanical aspects of marginal bone resorption around osseointegrated implants: supervise the project. All authors contributed to the article and approved the submitted version.

\section{FUNDING}

BIOTECH DENTAL company is gratefully acknowledged for its financial support on SD grant.

\section{ACKNOWLEDGMENTS}

The authors would like to thank Yulin Hao for the supply of TNZ alloy. They are also grateful to PIMM laboratory (ENSAM, CNAM, CNRS) for access to their instrumented indentation equipment.

considerations based on a three-dimensional finite element analysis. Clin. Oral. Implants Res. 15, 401-412. doi: 10.1111/j.1600-0501.2004.01022.x

Koshy, E., and Philip, S. R. (2015). Dental implant surfaces: an overview. Int. J. Clin. Implant Dent. 1, 14-22. doi: 10.5005/jp-journals-10004-1028

Kroger, H., Venesmaa, P., Jurvelin, J., Miettinen, H., Suomalainen, O., and Alhava, E. (1998). Bone density at the proximal femur after total hip arthroplasty. Clin. Orthop. Relat. Res. 352, 66-74. doi: 10.1097/00003086-199807000-00009

Kuroda, D., Niinomi, M., Morinaga, M., Kato, Y., and Yashiro, T. (1998). Design and mechanical properties of new $\beta$ type titanium alloys for implant materials. Mater. Sci. Eng. A 243, 244-249. doi: 10.1016/S0921-5093(97)00808-3

Laheurte, P., Elmay, W., Prima, F., and Gloriant, T. (2014). "Titane et alliages: Des matériaux de choix pour les applications médicales," in Techniques de l'ingénieur (M4781). Available online at: https://www.techniques-ingenieur. $\mathrm{fr} /$ base-documentaire/materiaux-th11/metaux-et-alliages-non-ferreux42357210/titane-et-alliages-m4781/ (accessed March 03, 2021).

Laing, P. G., Ferguson, A. B., and Hodge, E. S. (1967). Tissue reaction in rabbit muscle exposed to metallic implants. J. Biomed. Mater. Res. 1, 135-149. doi: $10.1002 / \mathrm{jbm} .820010113$

Li, S. J., Xu, Q. S., Wang, Z., Hou, W. T., Hao, Y. L., Yang, R., et al. (2014). Influence of cell shape on mechanical properties of Ti-6Al-4V meshes fabricated by electron beam melting method. Acta Biomater. 10, 4537-4547. doi: 10.1016/j.actbio.2014.06.010

Lin, D., Li, Q., Li, W., and Swain, M. (2010). Bone remodeling induced by dental implants of functionally graded materials. J. Biomed. Mater. Res. B. Appl. Biomater. 92, 430-438. doi: 10.1002/jbm.b.31531

Liu, Y., Bao, C., Wismeijer, D., and Wu, G. (2015). The physicochemical/biological properties of porous tantalum and the potential surface modification techniques to improve its clinical application in dental implantology. Mater. Sci. Eng. C 49, 323-329. doi: 10.1016/j.msec.2015.01.007

Mariani, P., Margossian, P., and Laborde, G. (2008). Choix d'un concept occlusal en implantologie-1ère partie : données fondamentales. Strat. prothétique 8, 145-153. Available online at: https://www.idweblogs.com/wp-content/ uploads/2013/06/10588_spvol8n1p5-13.pdf (accessed March 03, 2021).

Mehrali, M., Shirazi, F. S., Mehrali, M., Metselaar, H. S. C., Kadri, N. A. B., and Osman, N. A. A. (2013). Dental implants from functionally graded materials. J. Biomed. Mater. Res. A 101A, 3046-3057. doi: 10.1002/jbm.a.34588

Mimura, K., Watanabe, K., Okawa, S., Kobayashi, M., and Miyakawa, O. (2004). Morphological and chemical implant characterizations of the interface of a hydroxyapatite-coated implant. Dent. Mater. J. 23, 353-360. doi: $10.4012 / \mathrm{dmj} .23 .353$

Niinomi, M., and Nakai, M. (2011). Titanium-based biomaterials for preventing stress shielding between implant devices and bone. Int. J. Biomater. 2011:836587. doi: 10.1155/2011/836587

Okulov, I. V., Weissmüller, J., and Markmann, J. (2017). Dealloying-based interpenetrating-phase nanocomposites matching the elastic behavior of human bone. Sci. Rep. 7, 1-7. doi: 10.1038/s41598-017-00048-4

Oldani, C., and Dominguez, A. (2012). "Titanium as a biomaterial for implants," in Recent Advances in Arthroplasty (InTech). doi: 10.5772/27413 
Available online at: http://www.intechopen.com/books/recent-advances-inarthroplasty/titanium-as-a-biomaterial-for-implants. (accessed March 03, 2021).

Oliver, W. C., and Pharr, G. M. (1992). An improved technique for determining hardness and elastic modulus using load and displacement sensing indentation experiments. J. Mater. Res. 7, 1564-1583. doi: 10.1557/JMR.1992.1564

Oliver, W. C., and Pharr, G. M. (2004). Measurement of hardness and elastic modulus by instrumented indentation: advances in understanding and refinements to methodology. J. Mater. Res. 19, 3-20. doi: 10.1557/jmr.2004.19.1.3

Oshida, Y., Tuna, E. B., Aktören, O., and Gençay, K. (2010). Dental implant systems. Int. J. Mol. Sci. 11, 1580-1678. doi: 10.3390/ijms11041580

Piotrowski, B., Baptista, A. A., Patoor, E., Bravetti, P., Eberhardt, A., and Laheurte, P. (2014). Interaction of bone-dental implant with new ultra low modulus alloy using a numerical approach. Mater. Sci. Eng. C 38, 151-160. doi: 10.1016/j.msec.2014.01.048

Prima, F., and Nowak, S. (2012). Metallic Material With an Elasticity Gradient. Patent WO 2012/059895 A1. World Intellectual Property Organization (WIPO), Geneva. Available online at: https://patentscope.wipo.int/search/en/ detail.jsf?docId=WO2012059895 (accessed March 03, 2021).

Rao, S., Ushida, T., Tateishi, T., Okazaki, Y., and Asao, S. (1996). Effect of Ti, Al, and $\mathrm{V}$ ions on the relative growth rate of fibroblasts (L929) and osteoblasts (MC3T3-E1) cells. Biomed. Mater. Eng. 6, 79-86. doi: 10.3233/BME-1996-6202

Rieger, R., Hambli, R., and Jennane, R. (2011). Modeling of biological doses and mechanical effects on bone transduction. J. Theor. Biol. 274, 36-42. doi: 10.1016/j.jtbi.2011.01.003

Riley, M. R., Boesewetter, D. E., Kim, A. M., and Sirvent, F. P. (2003). Effects of metals $\mathrm{Cu}, \mathrm{Fe}, \mathrm{Ni}, \mathrm{V}$, and $\mathrm{Zn}$ on rat lung epithelial cells. Toxicology 190, 171-184. doi: 10.1016/S0300-483X(03)00162-8

Schneider, S., Schneider, S. G., Da silva, H., and de Moura Neto, C. (2005). Study of the non-linear stress-strain behavior in Ti-Nb-Zr alloys. Mater. Res. 8, 435-438. doi: 10.1590/S1516-14392005000400013

Schulze, V. (ed.). (2006). Modern Mechanical Surface Treatment: States, Stability, Effects. Weinheim: Wiley-VCH. doi: 10.1002/3527607811

Shi, L., Wang, L., Duan, Y., Lei, W., Wang, Z., Li, J., et al. (2013). The improved biological performance of a novel low elastic modulus implant. PLoS ONE 8:e55015. doi: 10.1371/journal.pone.0055015

Steinemann, S. G. (1980). "Corrosion of surgical implants-in vivo and in vitro tests," in Evaluation of Biomaterials, eds G. D. Winter, J. L. Leray, and K. de Groot (Chichester: Wiley), 1-34.

Sun, F., Hao, Y. L., Nowak, S., Gloriant, T., Laheurte, P., and Prima, F. (2011). A thermo-mechanical treatment to improve the superelastic performances of biomedical $\mathrm{Ti}-26 \mathrm{Nb}$ and $\mathrm{Ti}-20 \mathrm{Nb}-6 \mathrm{Zr}$ (at.\%) alloys. J. Mech. Behav. Biomed. Mater. 4, 1864-1872. doi: 10.1016/j.jmbbm.2011. 06.003

Sun, F., Nowak, S., Gloriant, T., Laheurte, P., Eberhardt, A., and Prima, F. (2010). Influence of a short thermal treatment on the superelastic properties of a titanium-based alloy. Scr. Mater. 63, 1053-1056. doi: 10.1016/j.scriptamat.2010.07.042

US Food and Drug Administration (2019). Biological Responses to Metal Implants. Available online at: https://www.fda.gov/media/131150/download (accessed March 03, 2021).

Walker, P. R., LeBlanc, J., and Sikorska, M. (1989). Effects of aluminum and other cations on the structure of brain and liver chromatin. Biochemistry 28, 3911-3915. doi: 10.1021/bi00435a043

Wally, Z., van Grunsven, W., Claeyssens, F., Goodall, R., and Reilly, G. (2015). Porous titanium for dental implant applications. Metals (Basel) 5, 1902-1920. doi: $10.3390 /$ met5041902

Williams, D. F. (1987). Definitions in Biomaterials: Proceedings of a Consensus Conference of the European Society for Biomaterials (ESB), Chester, England, March 3-5, 1986. Amsterdam: Elsevier.

Williams, D. F. (2003). Revisiting the definition of biocompatibility. Med. Device Technol. 14, 10-13. doi: 10.1016/S1369-7021(03)01019-8

Xue, T., Attarilar, S., Liu, S., Liu, J., Song, X., Li, L., et al. (2020). Surface modification techniques of titanium and its alloys to functionally optimize their biomedical properties: thematic review. Front. Bioeng. Biotechnol. 8:603072. doi: 10.3389/fbioe.2020.603072

Yue, S., Pilliar, R. M., and Weatherly, G. C. (1984). The fatigue strength of porouscoated Ti-6\%Al-4\%V implant alloy. J. Biomed. Mater. Res. 18, 1043-1058. doi: 10.1002/jbm.820180908

Zhang, J. Y., Sun, F., Hao, Y. L., Gozdecki, N., Lebrun, E., Vermaut, P., et al. (2013). Influence of equiatomic $\mathrm{Zr} / \mathrm{Nb}$ substitution on superelastic behavior of Ti-Nb-Zr alloy. Mater. Sci. Eng. A 563, 78-85. doi: 10.1016/j.msea.2012.11.045

Zhang, L. C., and Chen, L. Y. (2019). A review on biomedical titanium alloys: recent progress and prospect. Adv. Eng. Mater. 21:1801215. doi: 10.1002/adem.201801215

Zheng, Y., Zhang, B., Wang, B., and Li, L. (2012). "New kind of titanium alloys for biomedical application," in Integrated Biomaterials for Biomedical Technology, eds M. Ramalingam, A. Tiwari, S. Ramakrishna, and H. Kobayashi (Salem, MA: Scrivener Publishing LLC), 253-272. doi: 10.1002/9781118482513.ch6

Conflict of Interest: SD is employed by the company BIOTECH DENTAL.

The remaining authors declare that the research was conducted in the absence of any commercial or financial relationships that could be construed as a potential conflict of interest.

Copyright (C) 2021 Delannoy, Baïz, Laheurte, Jordan and Prima. This is an openaccess article distributed under the terms of the Creative Commons Attribution License (CC BY). The use, distribution or reproduction in other forums is permitted, provided the original author(s) and the copyright owner(s) are credited and that the original publication in this journal is cited, in accordance with accepted academic practice. No use, distribution or reproduction is permitted which does not comply with these terms. 